\title{
Unstandard deviation: The untapped value of positive deviance for reducing inequalities
}

Kai Ruggeri*, Columbia University, Mailman School of Public Health, Department of Health Policy and Management

Tomas Folke, Columbia University, Mailman School of Public Health, Department of Health Policy and Management

This version of the article has been accepted by Perspectives on Psychological Science and is due to be published in Summer-Autumn 2021.

Abstract

Behavioral science is increasingly used in public policy to understand and address various manifestations of inequalities. Yet evidence from effective population-level interventions is limited. One framework, known as positive deviance, emphasizes individuals from disadvantaged circumstances who have significantly better outcomes than are typical for their group. Studying their behaviors and outcomes helps to understand what might explain their overall success. It can also help to incorporate those insights in such a way that would facilitate others from these circumstances to experience positive outcomes. Because positive deviance has been markedly understudied, we present a framework for doing so specifically within behavioral science for public policies aimed at reducing inequalities. Using examples from real-world and experimental insights on choices and outcomes of positive deviants, we encourage further study of their choices and trajectories over time to produce valuable insights. We propose that leveraging those findings would inform public policy by introducing interventions that are more ecologically sound and population relevant, and consequently have a better chance at benefiting those who start off under adverse circumstances.

*Corresponding Author: kai.ruggeri@,columbia.edu 


\section{The problem with inequality}

Economic inequality - the uneven distribution of wealth within and between a population - is thought to be problematic for four primary reasons: 1) it gives undue power to a small number of individuals, 2) it reduces fairness in political institutions, 3) it harms general economic fairness, and 4) it excludes those partially responsible for economic growth from its benefits (Scanlon, 2018). Although increasingly studied in contemporary policy and research (Dietze \& Craig, 2020), and widely recognized around the world as among the most significant threats to modern societies (Pew Research Center, 2014), economic inequality is not a recent phenomenon; human societies have been economically unequal for as long as humans have lived in societies (Harari, 2014).

While income inequality between countries has been decreasing in recent decades as poor countries become wealthier, inequality within countries has increased (Niño-Zarazúa et al., 2017; Ortiz \& Cummins, 2011; Piketty, 2015). This has occurred and worsened even when large-scale resources have been allocated to improving national economic standards (Lang, 2020). Such inequality means that poverty persists even in societies that hold historically unparalleled levels of wealth (DeNavas-Walt \& Proctor, 2014), which worsens systematically unfair systems (Hill et al., 2017), particularly those with significant racial inequities (Sanders-Philips, et al., 2009).

Because individuals with lower incomes have fewer resources to absorb unexpected shocks, they often must focus on the present and be risk-averse (Haushofer \& Fehr, 2014; Hill et al., 2017; Morduch \& Schneider, 2017). Such tendencies are not irrational; these patterns are driven by the necessity of focusing on immediate challenges, making long-term planning difficult (Gneezy e al., 2020). In more technical terms, mental focus on proximal risk-avoidance increases cognitive load, leading to worse cognitive performance on other tasks, which in turn may increase suboptimal decisions (Gennetian \& Shafir, 2015; Mani et al., 2013; Schilbach et al., 2016). Together, high discount rates, risk aversion, and cognitive load make it harder to accumulate wealth, as saving and investment by definition require forgoing immediate certain rewards, for future, more uncertain ones (Bryan et al., 2017). Such resource scarcity does not only hamper wealth accumulation, but also risk 
management: when maximizing efficiency with constrained resources, disadvantaged individuals have limited capacity to plan ahead (Ludwig et al., 2019) that might hedge certain costs and risks over time (Haushofer \& Fehr, 2014). Yet, the impacts of these challenges are unclear (Ludwig et al., 2019).

The limited capacity to absorb shocks is not just psychologically detrimental to poor people themselves, but can create and exacerbate vulnerabilities of society as a whole (Dietze \& Craig, 2020), impeding economic growth (Atems \& Jones, 2015). By the time shocks occur, little can be done to protect the most vulnerable individuals, short of expansive institutional action, which can put entire populations at economic risk. Similarly, institutional inaction can force people to make suboptimal short-term decisions that might deepen ongoing crises. The quarantines and lockdowns resulting from the COVID-19 pandemic made these vulnerabilities globally salient in 2020 .

Greater psychological understanding of which factors enable some people to escape these adverse conditions (Frankenhuis \& Nettle, 2020), despite the structural challenges they face, could help identify strategies to support individuals and groups in the most disadvantaged positions (Alesina et al., 2018; LeMahieu et al., 2017, Pascale et al., 2010). Here we present an area of research that has been largely overlooked in the psychological and behavioral sciences that offers a means of addressing the consequences of pervasive social and economic inequalities, and disrupting their propagation: positive deviance. While this approach alone will not erode the existing social, racial, economic, and educational barriers that have played a major part in creating harmful inequalities, effective application should contribute toward mitigating their impact. In this paper we set out to 1) introduce the concept of positive deviance as it has been used elsewhere in the social sciences, 2) argue for its utility to psychological research in general and behavioral public policy in particular, and 3) provide a blueprint for researchers how to apply a positive deviance framework to their own research. 


\section{Positive deviance}

To reiterate, economic inequality impacts not only those in poverty, but more broadly, to individuals and households substantially below median income and wealth, whose ability to endure costs of living is a constant struggle. In these disadvantaged groups, there is typically a small group of outliers who have much better outcomes than their peers. Medicine and epidemiology developed methods to study these outliers to design better interventions under a framework known as positive deviance (Wishik \& Van der Vynckt, 1976; Zeitlin et al., 1990; also see Marsh et al., 2004), with positive effects in clinical and public health (Zanetti \& Taylor, 2016). Positive deviance typically refers to the research framework to study positive outliers — sometimes referred to as positive deviants — but it can also be used to refer to the behaviors that set these outliers apart from their peers. To avoid confusion, we will use positive deviance exclusively to refer to the framework, and explicitly refer to positive deviants as individuals whose outcomes positively deviate from (likely negative) norms. When referring to behaviors, choice patterns, or other factors that set these groups apart, we list these explicitly.

One example of positive deviance comes from the 1990s, when Save the Children developed a program to improve childhood nutrition (Zeitlin et al., 1990). Practices of caregivers of relatively better-nourished children were observed; these practices and behaviors were then taught to other caregivers. A randomized controlled trial of more than 100 children per group found that children in the positive deviance condition were half as likely to suffer respiratory illnesses associated with malnutrition relative to children in the controls (Sripaipan et al., 2002).

In spite of the clear relevance of positive deviance to both science and policy, it is under-studied compared to popular behavioral policy interventions. For example, Web of Science searches for "choice architecture" in early 2020 produced nearly 14,000 hits and over 5,000 for "nudge", but only around 1,000 for "positive deviance". Positive deviance itself is not a specific intervention technique in the way nudges are, so this comparison is not like-for-like. However, the imbalance is noteworthy because positive deviance predates the popularity of nudging and because uneven effects of such behavioral interventions are well-known (discussed later). Furthermore, literature from disparate fields such as nutrition (Feng \& Bruin, 2016; Mackintosh et al., 
2002; Roche et al., 2017), education (LeMahieu et al., 2017), management (Spreitzer \& Sonnenshein, 2004), and - most notably - healthcare (Bradley et al., 2009; Marsh et al., 2004) has made largely unheeded calls for greater empirical and experimental testing of the positive deviance framework. Of those studies on positive deviance, many are from grey literature, use overly broad (or unrelated) definitions of positive deviance (e.g., equating it with counter-normative behavior, rather than emphasizing outcomes relative to circumstances), or provide only anecdotal findings. Very few include empirical insights on choices or behavior.

While nudges and boosts are popular at present, literature on these subjects highlights the tendency to overrely on them as a solution to major social challenges related to decision-making (Heilman, 2014). Nudges alone will not make a major impact on structural public health problems such as poverty, anti-vaccination beliefs, or even tobacco use (Loewenstein \& Chater, 2017). Similarly, traditional policy approaches such as taxation and labeling have likewise only been partially effective. Inversely, the majority of work on positive deviance has been conducted in developing countries and focused on extremely disadvantaged populations in the Global South (Albanna \& Heeks, 2019), meaning there is a lack of evidence on their potential in addressing matters of inequality more broadly.

Standard behavioral interventions are blunt: they encourage behaviors that are beneficial to the modal person but might actually hurt those that are worst-off. One intervention that encouraged savings led to people dealing with financial shocks by taking out high-interest loans rather than utilize their savings, lowering their overall financial well-being (Sussman \& O’Brien, 2016). These asymmetries make a strong argument for using the positive deviance framework, as substantial literature on the psychology of inequality highlights the unique behavioral barriers faced by those worst-off (Haushofer \& Fehr, 2014; Mani et al., 2013; Schilbach et al., 2016).

The relative neglect of positive deviance in behavioral research is particularly relevant because positive deviance might help address a pressing problem in behavioral public policy: Psychological interventions that have demonstrated effectiveness among the general public tend to be less successful for disadvantaged populations, 
who in theory stand to benefit the most (Ruggeri et al., 2020a). While less concerning than the savings plans example, health centers sending out text-based reminders increased attendance by $29 \%$ on average, according to a recent review (Hasvold \& Wootton, 2011), but when the same intervention was directed towards a disadvantaged population (which typically has greater risk of illness and disease), it had no significant effect (Chaiyachati et al., 2018; Ruggeri et al., 2020b). This leaves a critical opening for other behaviorally informed methods to tackle pressing public policy challenges, while building from the tremendous wealth of behavioral evidence available (van Bavel et al., 2020). Positive deviance provides an ideal framework for doing this.

\section{Dynamic distinctions of positive deviance}

It is critical to distinguish positive deviance from similar paradigms early on: by definition, a deviant must face the same resource limitations and structural barriers as the comparison group but with better outcomes (Singhal \& Dura, 2017). An obvious concern with the positive deviance approach is that if applied carelessly, it might obfuscate the distinction between correlation and causation: a person that has moved from minimum wage to the top income quantile might have made that transition because of clever choices, a supportive environment, or simply luck. Similarly, if we focus only on individuals observed to have achieved good outcomes, we run the risk of survivorship bias, in which we assume that behaviors shared by members of this group are distinct from the behaviors of less successful individuals, and that these behaviors caused the positive results.

Some of these concerns can be addressed quantitatively by comparing positive deviants to a control group, assuming the control group is appropriate. The key consideration with picking an appropriate control group is to ensure that they face similar resource constraints and barriers as the positive deviants, at least at face value. Of course, it is impossible to rule out that positive deviants differ structurally from controls in ways that might explain differences in outcome, but the point is to ensure that their life circumstances are not obviously different, as that would undermine any search for other causal factors. Even with appropriate control, it is not always clear whether a behavior produced better circumstances, or better circumstance led to a new behavior. This question can only be answered by careful longitudinal assessment or experimental work. Additionally, 
some behaviors that may be strongly associated with positive deviants only need to occur on rare or occasional circumstances, like annual flu shots or signing up for a $401 \mathrm{k}$ when starting a new job. They may be relatively uncommon in disadvantaged communities, but they may only be superficial or ambiguous indications of true deviation from the norm.

For these reasons, we note the limitations and risks of work in this field, and recommend that early stage research employ quantitative, longitudinal methods where possible (Pascale et al., 2010), and that mature research programs combine multiple streams of evidence and research methods before making causal claims. Qualitative approaches, though potentially useful for hypothesis generation (Heatherton \& Nichols, 1994), would amplify these biases: individuals are unlikely to be fully aware of what factors (particularly systemic) most benefited them, and would lack comparator groups (Davidai \& Gilovich, 2016).

\section{The study of positive deviance as a way forward}

It is not immediately clear what enables, precedes, or causes the success of positive deviants. Outcomes may relate to dispositional factors, subtle differences in circumstance, or luck. However, it may also relate to distinct choices, behaviors, and habits, which allow these individuals to navigate a challenging environment more successfully. Given the lack of empirical understanding of positive deviants, their choices, and their outcomes, Bradley et al. (2009) suggested a four-step process for studying positive deviance and identifying key inflection points:

1. Identify positive deviants to have clearer parameters for what is a true deviation, and what is shortlived or inconsequential to overall circumstances.

2. Study these positive deviants in depth to generate hypotheses as to why they have better outcomes while facing the same structural constraints as others in the target population.

3. Design and evaluate interventions based on these hypotheses.

4. Test the generalizability (and sustainability) of the most successful interventions. 
These steps enable study of positive deviance across a variety of behavioral domains, particularly as a complement to widely studied paradigms of decision-making. Importantly, positive deviance methods are atheoretical in that they do not necessarily include or preclude specific psychological theories. However, they do provide a way to determine which psychological constructs are most helpful in mitigating the effects of poverty by studying ways in which positive deviants differ from other members of the same population.

For this manuscript, we focus on relevant core psychological concepts, such as rational choice models and temporal discounting, though many other relevant constructs should eventually be considered. (We note some concern with the term "rational" in this context: the considerable challenges faced by all individuals, let alone those worst impacted by systematic barriers and inequalities, may understate the realities of complex choices under risk. It may be problematic to assume a higher expected value is a sufficient proxy for rational choice.)

Using the Bradley et al. framework (see Supplement 4 for visual depiction), we explain how core concepts of the positive deviance framework can be applied to behavioral science, presenting relevant theory and complementing it with data. For identifying positive deviants, we list which operationalizations are helpful for studying positive deviance in a behavioral context. We specify key constructs that need to be defined, such as origins and baselines, outcomes of interest, and critically exceptional, sustained behaviors. To the extent possible (see Challenges and limitations), we limit our characterization of positive deviance to upward change sustained over time: the longer a change is sustained, the less likely it is to be caused by randomness. This approach allows for isolating systemic factors enabling or obstructing those changes, while also identifying predictors of baseline reversion, both of which will be critical in developing our interventions.

Next, in studying individual positive deviants, we argue that the most relevant behaviors to assess are those that present meaningful links between the origins of deviants and their outcomes, such as long-term financial habits. In the experimental section, we provide example data on differences in choice patterns between positive 
deviants and controls from similar circumstances. These results could directly inform existing behavioral approaches, such as nudges and boosts, with direct implication for real-world applications. Finally, in the generalizability section, we discuss the potential value for policy uptake through leveraging positive deviance.

\section{Identifying positive deviants}

The first level at which psychological science can make a meaningful contribution to enabling greater positive deviance is by developing more standardized classifications for identifying positive deviants. To reiterate, positive deviants are people who do well on target outcomes despite being substantively disadvantaged. Target outcomes may include wealth accumulation, academic performance, or effectively managing a chronic disease. "Disadvantage" is even more nebulous, but must be relevant to the outcome of interest. In the simplest case, it means that positive deviants belong to one or several groups that statistically underperform on the outcome measure without underperforming themselves. In other words, they are statistical outliers on the outcome measure relative to their reference group, if not relative to the population at large.

By their nature, positive deviants must be identified by origins and outcomes, rather than by mechanisms or transient circumstances. In other words, "positive deviant" is a descriptive label; the causes of their outlier status are explored later in the research process. We intentionally present some latitude in this definition as to not limit researchers who want to apply this framework to their own interests, but rather provide some general guidelines to improve the likelihood that such attempts are fruitful. To illustrate, most people in a longitudinal survey from the lowest income quintile in 1994 remained there 10 years later, whereas only around 4\% percent of that population were in the highest quintile ten years later (ACS \& Zimmerman, 2008). To identify someone as conclusively deviating in a positive way, there must be a sustained shift from negative circumstances to either better circumstances or meaningfully (i.e., consequentially) better choices, and not momentarily identified by proxy or by a choice pattern that is generally common in the group. We also note that positive deviance is not exclusively or canonically about 'rags to riches', such as is depicted in Figure 1, or from the lowest quarter to 
the highest, as surveyed by Starmans et al (2017), but simply indicates a robust improvement to a sustainable level relative to a clearly disadvantaged start.

Contrarily, receiving a windfall that shifts economic class only temporarily, or engaging in a one-off optimal act to no wider effect, such as a single day of physical activity, are not sufficiently consequential to indicate deviance. By observing a sustained improvement over time, positive deviants are distinguished from those that see temporary improvements due to environmental volatility - although the specific timeline criteria will be, to some extent, arbitrarily defined. However, even an arbitrary time threshold ensures better identification of individuals that persevere in spite of that volatility, such as optimal leveraging of windfalls. Defining positive deviants this way requires high-quality time series data over an extended period. In many ways, this illustrates a best-case scenario; in later sections, we discuss how positive deviants can be identified when such data are unavailable.

\section{Illustrations of positive deviants in wealth and health}

Using income data from the Panel Study of Income Dynamics (PSID) for heads of household between 1968 and 1989, we illustrate positive deviance sustained over decades. Of those in the lowest income quintile in 1968, $1.5 \%$ had reached and remained above median income over the second half of this period. 
Figure 1. Earnings trajectory over 20 years for the bottom quintile of household heads in 1969 (Source: PSID).

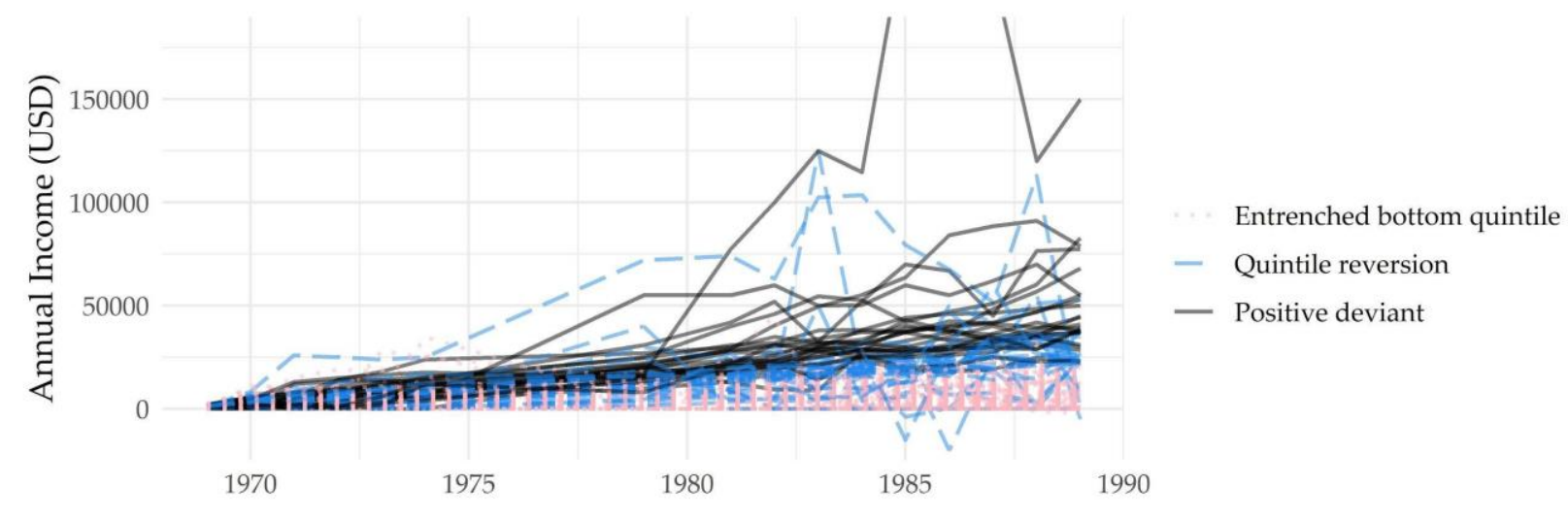

The 737 heads of household within the bottom quintile of earnings in 1969. The solid black lines represent the 1.5\% of these that had reached the top two income quintiles by 1985 and who were still there in 1989. Another 1.5\% of the sample bad, at some point, reached the top two quintiles but then reverted. We label these as "Quintile reversion".

Positive deviance can also be operationalized independent of wealth outcomes (LeMahieu et al., 2017). For example, in the context of domains such as healthcare and education, people from disadvantaged backgrounds face additional barriers to preferable outcomes (Dickman et al., 2017; Gary, 2005; Solga, 2014), which are magnified for people of color (Carey, 2019; Hong et al., 2007; Megija-Smith \& Gushue, 2017). In such settings, people that consistently carry out ideal behaviors (eating well, attending preventive appointments, doing homework, etc.) despite additional barriers can be viewed as positive deviants. In such contexts it is also appropriate to operationalize positive deviance through beneficial behaviors rather than outcomes, but consistency over time is still a key criterion to guard against false positives.

To illustrate how this can be applied to the context of health, we use data from a network of 15 federally qualified health centers in New York City covering over 900,000 appointments from over 100,000 low-income, predominantly minority patients, dating from January 2017 through June 2020. Here we operationalize positive deviants based on preventive appointment attendance. Preventive appointments are an established low-cost method to reduce unwanted health outcomes, yet our clinical data show significant variability between income groups, even within a geographically homogenous population. In the wealthiest subset of this population (which 
is still very low-income), only 32\% consistently attended their preventive appointments from 2017 to 2019 . In the lowest income group, who make up $60 \%$ of the patients in this network (the majority of which reports an income of $\$ 0$ annually), this drops to only 5\% (see Figure 2), which is substantially lower than the aggregate total of $20 \%$.

Figure 2. Appointment attendance by income level 2017-2019.

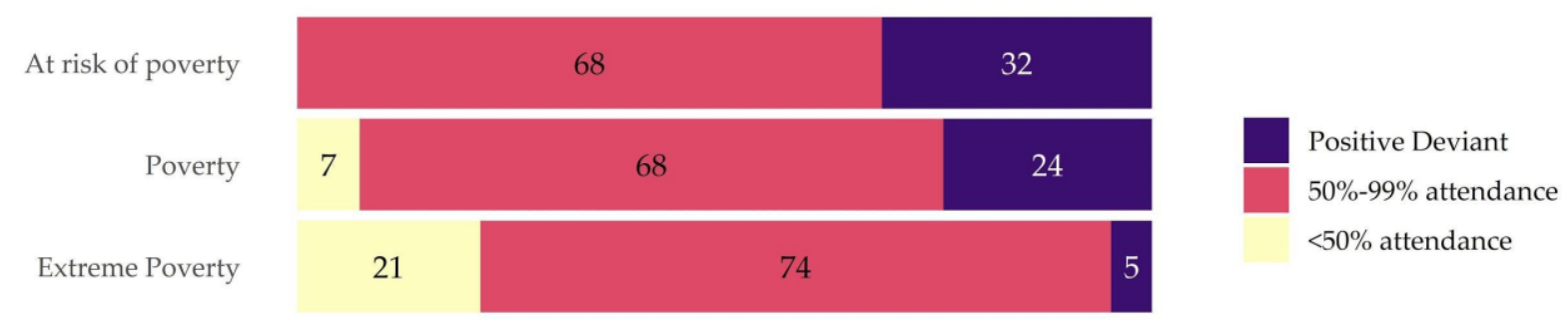

Percentage of Patients

All patients with at least three preventive appointments from 2017 to 2019. Important to note that all patients are generally lowincome, and $100 \%$ attendance is a strict criterion for positive deviance, but useful for illustration.

Going forward, we recommend operationalizing positive deviants through combinations of related behaviors. In the context of health, this could mean consistently attending preventive care, receiving vaccinations, and updating insurance choices during open enrollment. Those from disadvantaged positions who yet perform better than the population norm across the target behaviors could reliably be considered positive deviants. Foundational research that classifies positive deviance based on multiple sustained behaviors may give rise to a more robust understanding of the process that enables positive deviance. With such an understanding, it would eventually be possible to use inflection points (see Discussion) to reliably distinguish positive deviants based on critical decisions, behaviors, or achievements at given points in time, which we discuss next.

\section{Study positive deviants}

Once reliably identified, the next step toward advancing research on positive deviance is to better understand the environments, barriers, choices, and behaviors associated with the outcomes of interest. While there exists 
a literature on the psychological consequences of poverty and inequality (Haushofer \& Fehr, 2014), research is critically missing for understanding which behaviors and contexts facilitate - or obstruct - deviance. For example, consider how the disproportionate burden of chronic debt plaguing low-income populations escalates inequalities (Mian \& Sufi, 2015). This burden means that low-income people who manage to pay off debt regularly are a minority, which is exacerbated by unfair financial systems. To understand how some individuals are able to persevere in spite of this environment and the many barriers is critical to understand.

One inexpensive method for gaining preliminary understanding is using simple, traditional discrete choice experiments to determine if positive deviants have 'better' - or at least unique - decision patterns compared to others from similar circumstances. To illustrate this, we explore decision patterns using data from a recent study replicating the classic Prospect Theory experiment for 4,000 participants from 19 countries (see Ruggeri et al., 2020 for detailed methods and link to open data). Standardizing by country, we focus on 1,403 lower-income participants (Participants with incomes over half a standard deviation below the mean of the logarithm income at the country level), in which only $25 \%$ reported regularly paying off all credit balances monthly (compared to $40 \%$ in the full sample). For illustration purposes, we consider this small group as potential positive deviants, as such debt management is optimal in spite of sub-optimal circumstances in which the clear majority end up in a worse position (i.e., not paying off and therefore paying more interest, worsening their circumstance). There is no statistically significant income difference between the $25 \%$ who pay off their debt and the $75 \%$ who do not (Welch's $\mathrm{t}(1353.8)=0.7, p=0.48)$, who therefore can serve as an appropriate reference group.

Using the seven discrete choice items (see Supplemental Materials 1) in which there is a difference in expected values, a one-way between participant ANOVA revealed that there were significant differences in the propensity to select the highest expected value option between people with at least average income, low-income people who were in debt, and positive deviants (Figure 3; $\mathrm{f}(2,3626)=5.5, \eta^{2}=.003 p=0.004$ ). Tukey's test for honest significant differences revealed that positive deviants made significant more maximum utility choices than other low-income people ( $4 \%$ greater probability of making an optimal choice, $95 \% \mathrm{CI}=1.2-7.1 \%, p=$ 
$0.003)$ and high-income people $(2.9 \%$ greater probability of making an optimal choice, $95 \% \mathrm{CI}=0.2-5.7 \%, p$ $=0.03)$. There was no significant difference between high-income people and low-income people in debt $(1 \%$ greater probability of making an optimal choice, $95 \% \mathrm{CI}=0.5-3.0 \%, p=0.25)$.

While the magnitude of these effects are not substantial, they are robust in their consistency across all choices. This is important because small but consistent differences like these have the capacity to lead to vastly different outcomes, as choices compound. We stress that these results are only for illustration, but present a starting point for how psychological methods can be used to better understand potentially unique features of positive deviants.

Figure 3. Positive deviants are more likely to optimize long-term payoffs

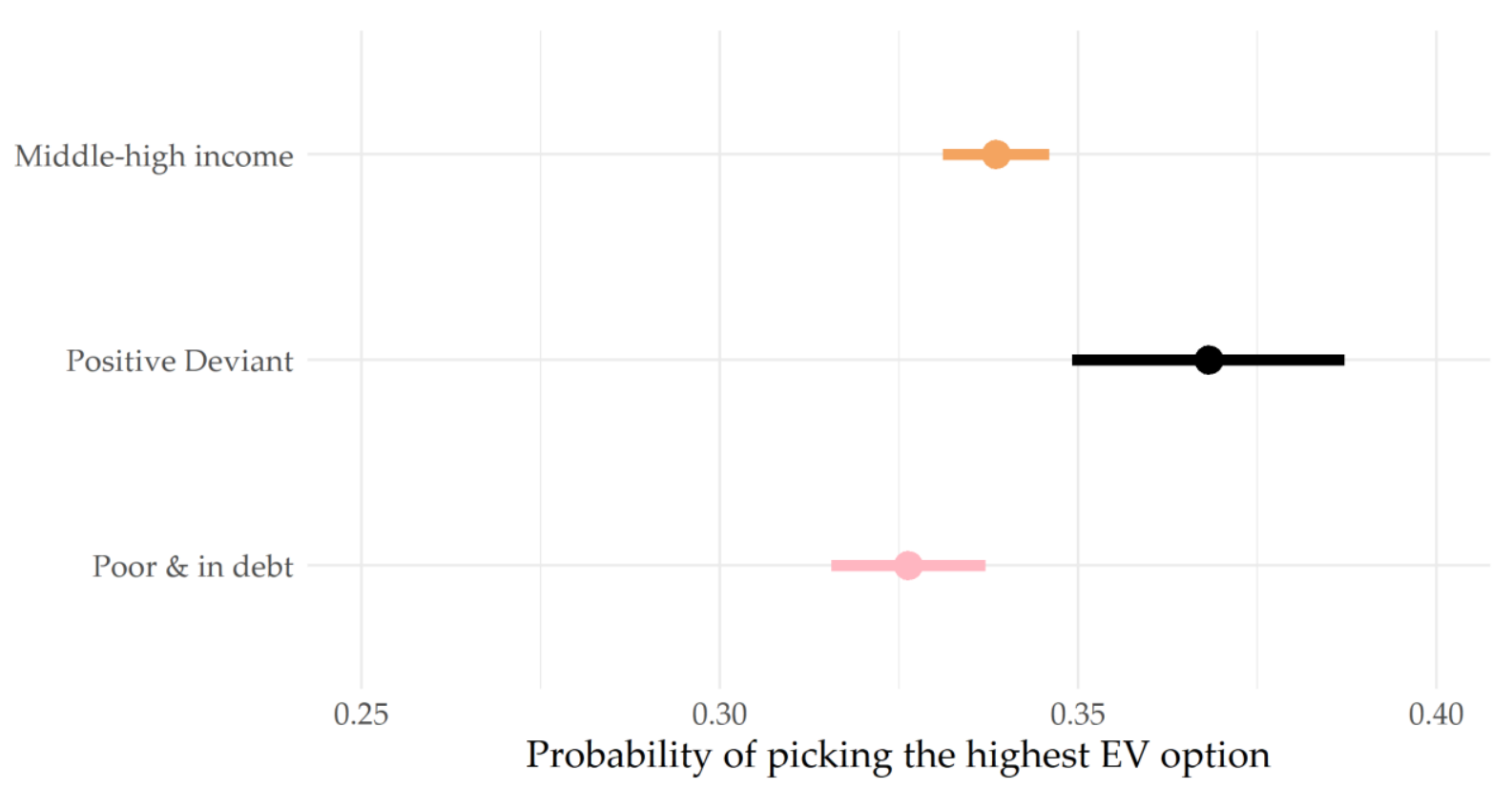

Participants are separated by income relative to their country of residence from a multinational replication study of Prospect Theory. Participants who reported paying off their debts despite being low income were more likely to pick options with higher expected values among the items where options differed in terms of expected values.

To further illustrate how behavioral science may capture the decision-making processes of positive deviants, we ran a simple additional experiment, including the original Prospect Theory items, several additional discrete choice measures, and questions about broad financial behaviors, complemented with measures of general financial circumstance. We classified positive deviants as individuals who self-reported having low-income 
homes as children but were able to cover all their monthly expenses as well as manage credit and debt effectively as adults (for exact item formulations, see Supplementary Materials 3). The aim was to see if they made different financial choices relative to other people from similar backgrounds. We also compared them to people who reported growing up in middle- and high-income homes. We sampled 547 adults limited to the state of California in the US to generate a diverse sample in terms of immediate environment, wealth, and demographics (see Supplementary Table 1), but who share a common legal and economic system. Data were collected entirely on the Prolific platform. We want to stress that these results of this survey are again primarily intended to illustrate how positive deviance might be studied in quantitative psychology.

Using the criteria described, our sample included 67 positive deviants and 114 individuals who were born in low-income homes and remained in problematic financial circumstances at the time of the study (366 individuals were from average or above income childhood homes). Positive deviants had higher incomes $($ Welch's $\mathrm{t}(82.63)=5.25, p<.001)$, more assets (Welch's $\mathrm{t}(136.06)=2.11, p=.03)$, and lower debts $(\mathrm{t}(177.42)$ $=2.04, p=.04$ ) than other people from poor backgrounds, validating our operationalization.

Differences between groups were minimal or non-existent for the discrete choice items (for more information see Supplemental Materials $2 \& 3$ ). There was no difference in optimal choices for the replicated Prospect Theory items $(\mathrm{F}(2,540)=2.14, p=.12)$ or for simple risk attitude items for gains $(\mathrm{F}(2,540)=0.65, p=.52)$ or losses $(\mathrm{F}(2,442)=2.39, p=.09)$. We also did not find differences for choices involving windfall gains $(\mathrm{F}(2,532)$ $=0.04, p=.96)$. These null findings stand in contrast to the previously reported results from the prospect theory data. This discrepancy may be caused by stricter criteria for defining positive deviance in the California sample, but should not be treated as conclusive.

However, where there begins to be considerable separation between positive deviants and other low-income individuals is how they report allocation of regular spending. Figure 4, depicts how participants report discretionary spending (funds left over after all bills paid) allocated to savings, investment, debt, and non- 
financial expenses (e.g. entertainment, miscellaneous). Notably, positive deviants differed in what proportion of discretionary spending they report devoting to savings and investments $(F(2,540)=23.89, p<.001)$. Specifically, positive deviants devoted a greater proportion of income toward savings and investments relative to other people from low-income backgrounds $(\beta=27 \%(4 \%), \mathrm{t}(540)=6.51 p<.001)$, and even more than people from middle-class or wealthy backgrounds $(\beta=11 \%(4 \%), \mathrm{t}(540)=3.15 p<.001)$.

Figure 4. Positive deviants spend more on savings and investments than other people from low-income backgrounds or people from high-income backgrounds.

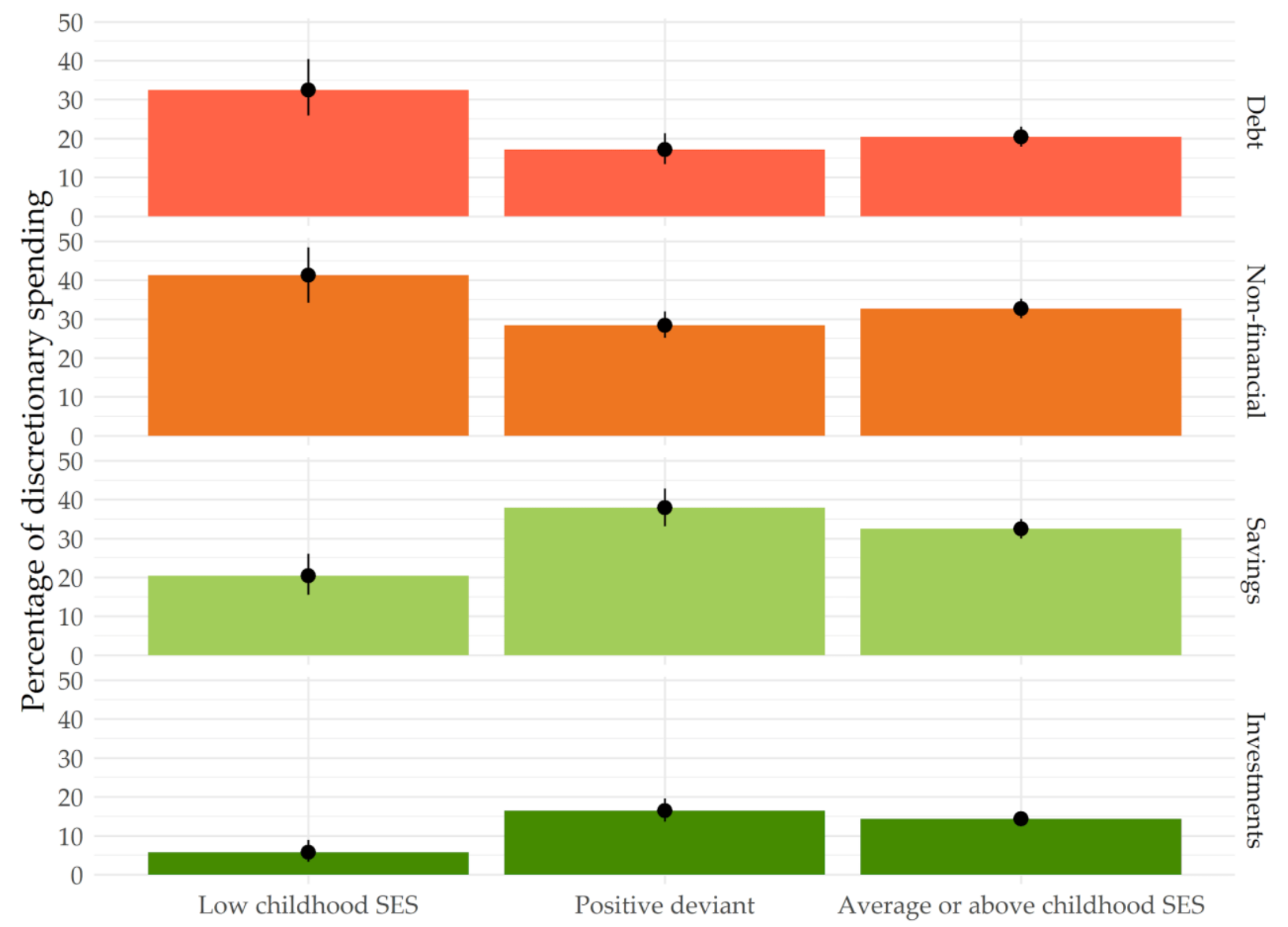

Self-reported discretionary spending after monthly expenses are covered. Positive deviants report spending less money on non-financial expenses and more money on savings and investments relative to other people from low-income backgrounds and people from highincome backgrounds. Error bars indicate 95\% bootstrapped confidence intervals. 
Exploring further across the four categories, positive deviants reported allocating less toward debt management and non-financial expenses than the other groups. While these have the inherent concerns of self-report, we note that participants were not aware of what classification they were given, and spending allocation came before most questions related to financial circumstances. Noting this, these results imply that positive deviants may build greater financial well-being over time by consistently setting aside (proportionally) more money for saving and investment relative to their reference group.

Reported allocation findings also seem to valid the notion that positive deviants discount future events less (i.e., value them more), which we assessed directly using six items. Two items were classical discounting items where participants chose between a smaller reward sooner or a greater reward later. For the remaining four items, participants chose between a smaller lump sum and a greater amount distributed over multiple installments. These items differed as to whether the amounts referred to gains and losses, and whether the lump sum was due at the beginning or the end of the smaller installments.

For the classic discounting items, positive deviants preferred larger, more distant rewards, over smaller immediate rewards $(\mathrm{F}(2,540)=5.46, p<.001)$, relative to other participants from low-income backgrounds $(\beta=0.20(0.06), \mathrm{t}(540)=3.27 p=.001)$ as well as to participants from high-income backgrounds $(\beta=0.11(0.05)$, $\mathrm{t}(540)=2.05 p=.04)$. For the remaining four items, positive deviants consistently preferred the smaller lump sums for both gains and losses (see Figure $5 ; \mathrm{F}(2,540)=9.71, p<.001)$. In this, they showed similar preferences to people from middle- and high-income backgrounds $(\beta=0.07(0.04), \mathrm{t}(540)=1.90 p=.06)$, but differed significantly from other people from low-income backgrounds $(\beta=0.18(0.04), \mathrm{t}(540)=4.10 p<.001)$. It is important to note that these preferences are not strictly optimal: positive deviants prefer a smaller gain paid in lump-sum over a greater amount distributed over a year, even when the lump sum would be paid at the end of the year. Traditional temporal discounting cannot account for this preference and an exciting path for future work would be to explore what drives this peculiarity along with the circumstances in which it might prove optimal in a way that utility values cannot estimate. The similar choice patterns between positive deviants and 
high-income participants also raises questions about the timing of studying outcomes: would the positive deviants have made these same choices while still low-income, or is the choice pattern simply indicative of those with currently greater wealth? We strongly encourage work that elucidates this timeline.

Figure 5. Positive deviants prefer lump sums over multiple installments, both for gains and losses, and independent of whether the lump sum is paid at the time of the first or the last installment.

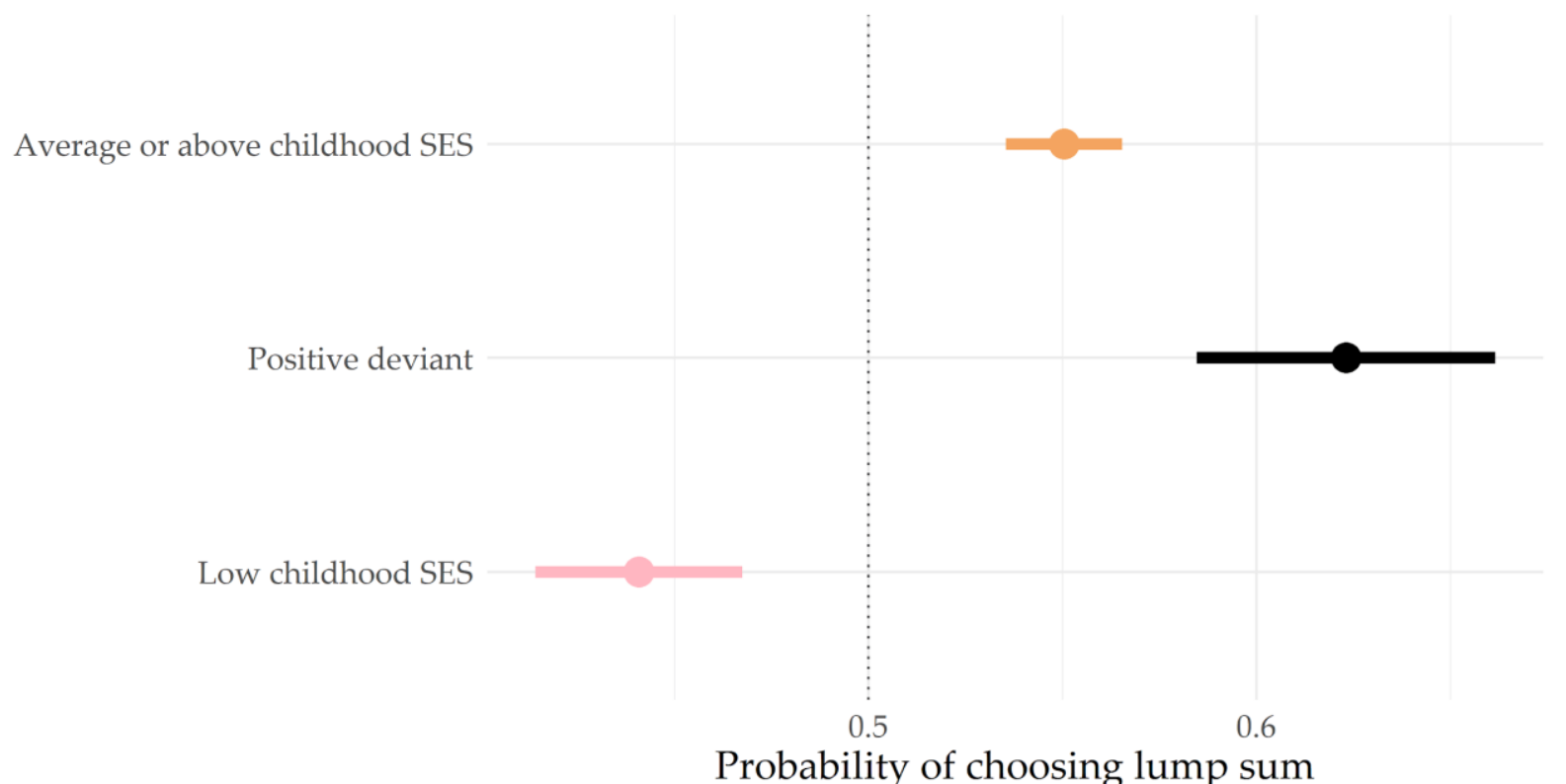

Probabilities of choosing a lump sum rather than multiple installments. Positive deviants strongly prefer lump sums over multiple installments, for both gains and losses, whereas other participants from low-income backgrounds show the opposite pattern. Selfreported discretionary spending after monthly expenses are covered. Error bars indicate $95 \%$ analytical confidence intervals.

We reiterate that these preliminary insights are for illustrative purposes. They were interestingly counter to our expectations in terms of direction, but it is nonetheless critical that they are independently validated and replicated prior to informing policy applications that leverage and enable greater positive deviance. 


\section{Design and evaluate interventions}

It is not entirely clear why positive deviance has not been widely studied generally or within social and psychological sciences. One possible explanation could be that most work on inequalities and public policy tends to focus on aggregate group differences, such as gender gaps in wages or uneven funding of education systems based on race or local income (Lewis \& Yates, 2019). Understandably, work on those fields has sought to understand the impact on the population of inequitable systems, yet potentially missed out on learning from those that were able to flourish in spite of them.

Race, funding for education, wage gaps based on gender should all be explicitly incorporated into the study of positive deviance. While some level of inequalities have always existed and some always will, scientists and policymakers should not focus their work on interventions that simply minimize the effects of bad policies rather than to replace bad policies outright (see Challenges and limitations). However, the under-utilization of positive deviance means there is untapped potential to leverage the scaffolding created by ongoing movements (such as behavioral policy units and evidence-based policy legislation) to integrate more empirically validated behavioral policy interventions to support those who may benefit most. With better classification of positive deviants and potentially robust research on distinct behaviors, there will be greater opportunities to apply such insights into those interventions.

Insights from positive deviants can be applied to behaviorally-informed public policy by utilizing nudges, which are small changes in choice architecture that increase the likelihood of optimal choice (Thaler \& Sunstein, 2009). In situations where there is no obvious optimal choice, or the optimal choice varies from person to person, simple interventions to increase choice-relevant competencies and deliberation, known as boosts, (Hertwig \& Grüne-Yanoff, 2017) could be applied. Existing interventions from both nudges and boosts also present a scaffolding for incorporating positive deviance, such as by adjusting normative recommendations to match individuals to more similar groups or assisting with calculations that reflect more realistic allocation plans for 
lower-income homes. However, in our own work compiling over 250 behavioral policy cases (Ruggeri, 2019) which included nudges, boosts, and other approaches - we found no examples of positive deviance being incorporated into any strategy or evaluation.

To date, the concept of positive deviance has instead been largely studied from a sociological perspective (Heckert \& Heckert, 2002), and is most commonly applied to public health topics (Marra et al., 2010). These approaches highlight existing behaviors that are associated with good outcomes despite challenging circumstances. For example, Bradley et al. (2009) identified clinics that were exceptionally good at providing care for myocardial infarction. Using a survey, they found differences in behavior that distinguished the successful locations, then provided those practices as recommendations to other clinics. This approach resulted in substantial improvements in adherence to best practices as well as improvement in standard performance metrics of care. Their success was attributed to hospitals being provided a model of optimal behavior from clinics with similar resource limitations, rather than a model based on ideal, and seemingly unrealistic, circumstances. Like most prior work on positive deviance, this study focused on institutional behavior, but the same conceptual framework can be useful when applied to individuals.

In the context of behavioral science, this approach could be implemented in numerous ways. Perhaps the most obvious intervention would be disclosing the choices, preferences, and strategies of positive deviants to other people from similar backgrounds. Such interventions can be applied both in experimental and applied settings. For example, in our own work on nudges and boosts, we found that simple disclosure nudges that informed individuals about which risky choice was optimal had a positive impact on avoiding unnecessary losses (Franklin et al., 2019). Interventions leveraging social norms make use of such disclosures in multiple contexts, such as energy consumption and bill repayment, which could be tested in controlled experiments similar to the allocation task we describe here. To improve the implementation of that approach when specifically aiming to engage disadvantaged populations, normative disclosures could present choices of individuals from the same circumstances that experienced improved circumstances after (Sussman \& O'Brien, 2016). Where possible, 
personalization (Ruggeri et al., 2020a) of monetary values based on individual incomes rather than fixed percentages may amplify some effects.

The efficacy of such approaches is relatively straight-forward to test experimentally, though caution should be applied to findings. For example, in the context of Prospect Theory-style gambles (Kahneman \& Tversky, 1979), the choices made by the modal positive deviant could be highlighted to all participants. Researchers may then evaluate if this increased the aggregate expected value of participants exposed to the disclosure intervention. Critically, it would further determine whether people from disadvantaged backgrounds benefit more from such interventions (i.e., being informed of the choices of positive deviants, with their similarities also highlighted) relative to people from wealthy backgrounds. From available work, there is some evidence that these should have modest effects on those with the most extreme risk preferences at baseline (Franklin et al., 2019), which is encouraging in the sense that it may benefit those worst-off as well as the general population.

Disclosures relaying positive deviant behaviors have two advantages relative to more conventional messaging. The first benefit is psychological: rather than being presented with an "ideal" repayment plan that may be viewed as unrealistic, they are exposed to a plan that someone in a similar financial situation actually managed to follow, with salient features that include an appealing outcome. The second benefit is related but more pragmatic: providing people with financial advice that would benefit the modal person can backfire, because variations in circumstance may not only make the modal response suboptimal but harmful (Sussman \& O’Brien, 2016). By personalizing recommendations to match different income levels, some of these risks are mitigated. Such approaches have been tested hypothetically in credit card bills, indicating faster debt reconciliation may be achieved by informing people of the payment rate of positive deviants in the same income category (Salisbury \& Zhao, 2020).

In real-world settings, the same kind of disclosure nudges could be applied to improve the effectiveness of current techniques. For example, a recent study (Seira et al., 2017) found no effect on repayments by making 
interest rates salient, but moderate effects were found through comparison messaging. This leaves an opening to test positive deviance approaches for potential added effectiveness - noting that even marginal improvements may be consequential in low-income groups. Such insights have tremendous potential for other domains, such as repayment of student loans, where similar concerns are well-known and ripe for new intervention approaches (Looney \& Yannelis, 2015).

Lessons learned from positive deviants can also be implemented as boosts by encouraging deliberation and emphasizing the features that appear relevant to positive deviants. In the context of credit card payments, the behaviors of positive deviants may inform a boost feature that rapidly calculates payoff options for different timelines and values that participants can choose (Salisbury \& Zhao, 2020). For timelines, instead of seeing choices for minimum, full, or 'other' payment amounts, individuals can be shown the amount to pay if they want to be out of debt at a certain point in time (e.g., "Amount to pay off in 5 years"), which could be balanced with an option to see how much small changes might add up (e.g., "How quickly will I pay off if I pay \$XXX.XX monthly?”). Because our own work using discrete-choice experiments showed boosts were primarily effective for gains, choice scenarios involving losses (i.e., payments) may work best by including simple disclosure nudges, where they appear to effectively minimize damages (Franklin et al., 2019).

Applying positive deviance to interventions is not strictly limited to financial decisions or outcomes. Instead, it should be seen as a framework for encouraging decisions that are most likely to mitigate challenging circumstances. Ideally, positive deviance approaches would result in long-term outcomes that include elevated economic stability, but even near-term gains would be extremely valuable.

To use a real-world example, consider challenges faced in maintaining adherence and compliance with medication regimes, which are particularly prevalent among low-income patients (Mishra \& Gioia, 2011) and magnified by racial inequalities (Gerber et al., 2010). Classic behavioral interventions encouraging compliance typically take a normative approach to communicating optimal strategies (Östervall, 2017), assuming a base 
level of equity in health literacy and access to care which is not realistic for low-income populations (Batterham et al., 2016; Kangovi et al., 2013). A potentially more effective alternative to that normative approach would be for researchers to learn from individuals that have particularly strong medication compliance, and then incorporate their strategies directly - and visibly - into behavioral interventions.

One potential way to encourage compliance is through leveraging participation principles (i.e., having patients directly plan their regime with a healthcare provider). However, given the patterns of reduced temporal discounting among positive deviants presented earlier, a specific feature of interventions in public healthcare clinics could incorporate the timeline-specific value of greater adherence. Practically, this would mean making salient - whether through reminders or in the initial planning meeting - how every on-time dosage completed impacts immediate and longer-term health outcomes. Leveraging this optimal temporal discounting behavior would then be a direct value-add from studying positive deviants.

As with the financial example, the proposed methods can be trialed in controlled experimental settings prior to being rolled out in the real-world where they have direct consequences. For example, they can be tested on members of a healthcare clinic to encourage participation in a daily survey prior to testing on medication regimes. This allows, as discussed in the following section, for the necessary a priori validation of a method as well as potential to test replicability and generalizability ahead of consequential implementation.

\section{Test the generalizability of positive deviance interventions}

Once the general tractability of positive deviance-informed interventions has been established, there will need to be a robust approach to assessing generalizability. This does not mean that all findings must generalize to be useful - the purpose of the proposed interventions is to support disadvantaged groups that do not respond to other interventions, so even localized effects would be valuable. Furthermore, many interventions may only be effective or meaningful in specific contexts (Gangl et al., 2020), but this does not erase their value, just narrows their portability. Instead, the focus should be on the extent to which effects generalize for appropriate use, but 
not to discredit those that appear to only benefit select groups. Such assessments inform both science and policy in critical ways.

For salience, here we outline a stepwise approach to initial assessments that is necessary to understand the possible contributions of positive deviance within behavioral science as well as its limits:

1. At the most fundamental level, non-consequential experimental interventions should be independently replicated in similar samples to ensure basic reliability.

2. Once reliability has been established, the next step would be to focus on ecological validation, which would assess the real-world effectiveness of the interventions for the target population they are intended to benefit.

3. If such effectiveness can be determined in a real world-setting, the next level of generalization would involve evaluating how well slight modifications of the intervention work, as well as how well it works in similar but different settings.

4. For interventions found to be effective at a local level, assess generalizability at a larger, more dynamic scale.

The third step would also involve evaluating the extent to which positive deviance interventions - specifically designed to help those worst off - improve outcomes for people who are closer to the mode or the mean as well. It is not necessary for positive deviance interventions to generalize in this way, as their primary aim is to support groups that do not tend to benefit from more classic (existing, implemented) interventions. However, if they do work for broad segments of the population, this would highlight an interesting asymmetry: interventions designed for the mode fail to benefit the bottom quantile, but interventions designed for the bottom quantile benefit the mode. Such an asymmetry, should it exist, would clearly be a strong argument for further adaptation of the positive deviance framework.

Subsequently, for the fourth step, the ultimate assessment of generalizability would involve testing how well they work in radically different contexts. This step would also involve evaluating interventions in different 
countries, which might differ in administrative capacity, legal frameworks, relevant barriers, localized inequalities, and culture. We want to stress that the aim here is not to "prove" that the interventions work in every context, but rather to map out the conditions that determine their effectiveness, so that policymakers can apply them more wisely.

In taking this approach, the accumulation of evidence would present clear parameters on the effectiveness, value-add, and generalizability of incorporating positive deviance into psychological research toward the reduction of inequalities. Expanded to multinational testing and evaluation, we would then also be able to determine the "globalizability" of both the constructs and the methods.

\section{General discussion}

This article is meant as an open invitation and encouragement for behavioral researchers to use positive deviance concepts, particularly in developing methods to confront inequalities. It is not intended as a definitive statement on the value, bounds, or costs associated with using positive deviance in behavioral science as such judgements would be premature. Instead, we rely on a small number of case studies using real-world, survey, and experimental data to illustrate its potential.

Widening adoption of positive deviance in psychology could have immediate scientific value by providing clearer definitions of positive deviants in various contexts, before shifting toward experimentation and potential policy uptake. Given this current status, we focus our discussion on what we identify as critical (existing) psychological constructs for study, known and likely limitations where research could immediately inform methodological and empirical gaps, and concrete recommendations for next steps aimed at researchers interested in filling those gaps. We begin with critical constructs and considerations from psychological science for addressing inequalities. 


\section{Inequality is more than a money problem}

Inequalities across different domains often interact - economic, health, education inequalities each have significant impact on the others, and yet each can originate completely irrespective from others. For example, a generally healthy and intelligent child from a low-income family is more likely to have a lower quality primary education and more likely to experience psychological barriers to academic success than a child from higher income families (Claro et al., 2016). Such barriers may harm long-term economic prospects, which are also directly linked to health (e.g., lower access to care, higher probability of unhealthy behaviors) (Holzer et al., 2008). Even for those who reach eventual financial stability, protracted financial stress at youth is likely to result in problematic decision-making and other negative outcomes (Evans \& Kim, 2013).

Inversely, even when families have sufficient wealth, children with significant illnesses are likely to underperform compared to peers, which also impacts long-term outcomes (Evans et al., 2019). When a child has both financial distress and illness alongside early education, the negative effects are amplified, often to extremes. Because of these complexities, it is an oversimplification to treat inequality as purely a financial matter (Payne, 2017). To address such a wide range of concerns, the application of positive deviance to address inequalities should not exclusively focus on the financial domain. Candidate psychological constructs that are relevant to further study in positive deviance are plentiful and can be applied in education, health, employment, prosociality, civic participation, and beyond. Rather than to provide a systematic but incomplete list of potentially relevant constructs, we instead focus on some burgeoning areas of research that have produced directly relevant insights: temporal discounting, time poverty, boomerang effects, choice asymmetries, and agency.

\section{Temporal discounting}

The case studies we present suggest that positive deviants discount future events less compared to others from similar backgrounds. This fits with the extensive literature that resource scarcity encourages steep discounting 
for most people (though not always: see Ludwig et al., 2019), and that steep discounting negatively impacts wealth accumulation (Mani et al., 2013; Shah et al., 2012). However, the discounting of future events has impacts outside the financial domain. Many health behaviors require short term sacrifices (foregoing a dessert, going out for a run) for medium and long-term health gains (Daugherty \& Brase, 2010). Flu vaccines might serve as a good case study, in that they are an easily measured one-off behavior with a short-term cost but a medium term benefit. In fact, the benefit of a vaccine might be particularly beneficial to disadvantaged people, as the cost of being ill and missing work is likely more severe (de Francisco et al., 2015), as are the heightened health impacts (Hadler et al., 2016). Therefore, an important research question is how temporal discounting relates to flu vaccination and other health behaviors, and, more importantly, what strategies positive deviants use to improve health outcomes.

Similarly, when applied to education, there are myriad challenges for all students to perform well in school, which are severely exacerbated for young people from low-income and unstable households. Given the critical role of parental support for education in long-term outcomes, performance in schools is unambiguously an inflection point for positive deviants compared to other low-income individuals (Cignano, 2014). Unfortunately, the time, capacity, and structured home environment necessary for optimal educational outcomes is typically lacking for low-income children, which worsens if there is little encouragement from home to perform well.

Preparation for exams and completing graded coursework are classic examples of temporal discountingrelevant behaviors: for each given amount of time committed to study, there are increasing rewards in terms of long-term outcomes (Lee et al., 2012). However, the choice to invest the near-term cost (i.e., committing time to study) is not an option that all children have equally autonomous control over. In this way, we strongly recommend further study not only on temporal discounting behaviors themselves, but on the unequally distributed fundamental barriers to optimal choice that manifest at early age. This may shed further light on 
enablers of and barriers to positive deviance, particularly in terms of who may have the luxury of sacrificing near-term costs for long-term gains.

\section{The luxury of valuing time over money}

An added complication of inequality is that individuals who would benefit most from greater discretionary time are also least able to generate it (Rose, 2019). Discretionary time is a valuable asset that relates to periods of a given day, week, or other cycle that can be allocated freely without negative consequence (Goodin et al., 2008), such as the period between two work shifts where no immediate personal tasks are pressing. Discretionary time is critical for performance when returning to work, or when personal tasks are imminent; and its routine absence is known as time poverty (Harvey \& Mukhopadhyay, 2007).

To understand the importance of discretionary time, consider two attempts at playing Tetris, the classic video game. In the first attempt, each piece enters the top of the screen at a slow pace with ample distance before it must be fit in somewhere. There is time to position the current piece optimally, consider other options, and strategize in advance of the next piece. Alternatively, the second attempt involves the pieces moving at a higher pace, with less distance to where the fit must occur, and no time to consider the following piece or a wider strategy. Naturally, performance will consistently be better in the first scenario, including capacity to overcome mistakes. Unlike in Tetris, reality does not award bonus points for level of difficulty.

Evidence on time poverty indicates that, for the most disadvantaged, even maintaining an income level covering basic sustenance typically requires excessive numbers of working hours (Harvey \& Mukhopadhyay, 2007). This absence of discretionary time can create perpetual activation of psychological stress, overwhelming response systems that are primarily intended for acute stimuli (Evans \& Kim, 2013). Such chronic stress may explain, at least in part, why many behavioral interventions have limited value within disadvantaged populations, not least because they fail to consider the critical differences in time capacities of those most in need, and how such differences impact reasoning, particularly financial. 
According to the fundamental economic principle of fungibility, $\$ 100$ should be worth $\$ 100$ regardless of initial wealth. If an individual has limited resources and minimal discretionary time, gaining $\$ 100$ will most likely go to an immediate $\$ 100$ need (Baker et al., 2020). For an individual with greater wealth, immediate spending is an option, but they also have access to additional options such as saving, or leveraging the asset for greater income or greater discretionary time. For example, $\$ 100$ could be spent on convenience services that increase capacity to work (e.g., paid cleaning services, increasing childcare coverage) or applied to risk-reward investments, both of which actually create added value for the $\$ 100$. Neither of these points should be seen as criticisms of those in such a fortunate position, but instead are highlights of ways in which inequality propagates. A classic behavioral intervention could encourage an optimal tradeoff for how to optimize such spending, even when there are imminent needs.

Unlike an individual with limited resources, individuals with greater discretionary time have the advantage of opting for value-maximizing choices, as opposed to the lower wealth individual, who must focus on maximum efficiency. The latter approach to optimization cannot improve an overall position, only maintain status quo. In this way, wealth produces a paradoxical feedback-loop in which those with financial resources have the luxury of needing them less yet more ways to further increase their wealth, and the luxury of leveraging time as desired - and that luxury potentially enabling both better financial security (Kalenkoski et al., 2011; Masuda et al., 2020) and greater well-being (Whillans et al., 2016).

\section{Boomerang effects}

One unfortunately common occurrence in behavioral interventions has been that interventions that have shown general effectiveness, or been beneficial to certain groups, produce negative effects for others (Sunstein, 2017). These backfires are known as boomerangs, and were most notably highlighted by Schultz et al. (2007) when using social norms to encourage reduced energy consumption. In that study, normative messaging encouraged households with excessive consumption to reduce, with the reverse effect for those that had consumed less than average prior to the intervention. While this effect was resolved by incorporating injunctive social norms, boomerangs could potentially have dire consequences for interventions applied in highly disadvantaged 
communities. Similar concerns have been raised in relation to public health campaigns (Ringold, 2002) and consumer choice (Richter et al., 2018), as well as a long-held concern about the use of subjective norms within minority groups (Trafimow \& Finlay, 1996).

At present, we do not suggest any broad solution to avoid this issue, but raise it as a fundamental argument for encouraging substantial empirical validation prior to attempting consequential interventions. Ex ante policy evaluations may produce some insight about potential boomerangs, such as directly calculating the effect of encouraging individuals to always put $20 \%$ of monthly income to savings and determining the likely impact this would have on credit-based purchasing. Similarly, as presented in the example of choosing lump-sum values over multiple distributed amounts with greater aggregate value, there may be genuine reasons to choose a lower amount (now or in the future) that should be factored in, with additional attention paid to impacts in a lowresource population. No intervention should knowingly or naïvely risk eliciting worse outcomes for anyone, particularly those in adverse circumstances.

\section{Bittersweet asymmetry}

As classically highlighted by Kahneman and Tversky (1979), our choice patterns are not consistent between gains and losses, nor are they perfectly inverted. In fact, we appear to have largely asymmetrical preferences and abilities as they relate to financial decisions dealing with losses and gains (Kuhnen, 2015). Such asymmetry may have a critical impact - potentially outright mitigation - on all forms of behavioral interventions if it is assumed incorrectly that the same method can be applied in contexts irrespective of the gain-loss balance of the decision. As noted in the example of our work, we have illustrations of this effect: a disclosure nudge was more effective at helping decision-makers avoid losses whereas boosts were more effective in gain contexts for sub-optimal decision-makers.

This relative independence in preference also means that we have limited information on the applicability of successful interventions that have not been applied on both ends. For example, classic availability heuristics (Hauff et al., 2020) have been indicative for predicting that greater knowledge about a pension plan is positively 
related with investing in the plan (Hadar et al., 2013). However, the inverse result occurred when information about interest rates were made more salient in paying off debts (Seira et al., 2017). So while availability heuristics may be a relevant tool given the cognitive efficiency they offer for disadvantaged populations, their value is not necessarily uniform across financial decisions (Harris et al., 2016). We strongly recommend work that directly tests these effects more robustly.

Agency

In line with many arguments here, particularly those related to time poverty, there are clear concerns that resource scarcity may strain individual cognitive capacity. This is independent of ability, intellect, or even developmental factors, but results from the chronic pressures faced by disadvantaged people which impede deliberation and, relatedly, optimal choices. Recent work on agency - the number of options available to individuals in practice - indicates that there is a direct link between those capacities and tolerance for risk (Gneezy et al., 2020). That same work includes experimental results suggesting that merely being informed about a wider set of choices can reduce some effects of scarcity without materially widening the choice set.

Such insights could be relevant to interventions that seek to leverage positive deviance, though some caution is warranted. First, observing the behaviors of those facing severe scarcity facilitates mapping their choice sets, and validating if their options are limited. Informing those individuals of the availability of alternative options, including or even emphasizing choices of positive deviants, may increase their agency and would align with other arguments we have presented. However, adding options may backfire if they contribute to choice overload, so such interventions should be applied strategically. Collectively, the value of such interventions is unclear, given that there is some indication that recognizing more options may be beneficial but does not necessarily lead to making use of those options (Gneezy et al., 2020).

\section{Positive deviance, behavioral science, and public policy}

One benefit of the positive deviance framework that we have not yet covered is the way it links foundational behavioral research to public policy. Traditionally, the path from basic research to policy application is slow and iterative (Howlett et al., 2017; Ruggeri et al., 2020c). This is preferable to rolling out policies without a 
sufficient evidence base, but it is both time and resource-intensive. The positive deviance framework speeds up this process by creating a tighter coupling between behavioral research and policy. Specifically, it starts by looking to the real world to identify barriers that disadvantaged groups face and how some people mitigate or bypass them. Then it utilizes psychological theory to first find and validate candidate processes that might explain the observed behaviors of positive deviants, and then to find ways to elicit and support those processes in others. Finally, if the preceding steps go well, field applications can be evaluated. This loop from real world to theory to real world ensures a consistent intellectual focus on application, while situating the work in the context of psychological theory to allow for greater generalizability and adaptability.

\section{Challenges and limitations}

Prior to outlining various methodological concerns with the positive deviance approach, we emphatically state that no behavioral intervention should be prioritized ahead of correcting policies that entrench, galvanize, or otherwise create and enable systemic inequalities. No intervention to encourage more studying will have a greater impact than more equitable funding of schools. Similarly, free rides to healthcare clinics will not improve population health more than truly accessible, quality healthcare. Even in highly equitable systems, inequalities still occur, particularly across diverse, dispersed populations. Our argument is that positive deviance is worthy of further study, not that it can universally override bad policy or correct for lack of awareness that such inequalities exist (Kraus et al., 2019).

As the evidence base around positive deviance develops in the behavioral sciences, there will be multiple challenges that need to be managed. Because it mandates the study of positive outliers in disadvantaged groups, a first major challenge relates to accessing relevant samples. Working directly with disadvantaged groups is fundamental to understanding realistic processes and barriers. This is especially critical to avoid boomerang effects as described earlier in the general discussion. Furthermore, close collaboration with disadvantaged populations will allow researchers to understand better why certain approaches may not work and what barriers are in the way, as well as what interventions have already been attempted. 
In order to support lasting change and avoid false positives, it critical to factor in the longitudinal nature of the positive deviance. Short-term thinking has produced misleading, superficial effects in the past, such as focusing on getting unemployed individuals to register with a job center. This increased hiring among the group, only to return almost to baseline within months, as emphasis was placed on the registration and not on maintaining employment (Glen, 2015). Indeed, our own definitions of positive deviance have a minor contradiction that needs to be addressed in this context: the most robust classification requires sustained change over time, yet critical indications of positive deviance may come in the form of unlikely, narrow behaviors.

While these concerns can be directly addressed through study design and collaboration approaches, we have focused our writing on larger-scale barriers to introducing new forms of behavioral interventions. What has been discussed so far is not an exhaustive list, but instead, is what we recommend as promising entry points for psychological researchers interested in contributing either to the empirical base on positive deviance, or simply in further exploration of behavioral approaches to confront inequalities. Other relevant factors will include the physical and mental health of potential positive deviants (Sajquim De Torres, 2016), and the potential for differential effects not based on understanding or ability, but other cognitive factors (Arulsamy \& Delaney, 2020).

Finally, we want to emphasize the importance of only making rigid policy recommendations once a critical mass of converging evidence imply that the true generative process of the target outcome is well-understood. Furthermore, recommendations should be made on a level that aligns with the scale and effect of findings (Baumeister et al., 2017; Cialdini et al., 2009; Flake et al., 2017; IJzerman et al., 2020; Ruggeri et al., 2020c). Critically, even when such an understanding is present, it is essential that interventions are not deployed naively outside of the populations that have been studied prior to additional validation (Yarkoni, 2020).

\section{Recommendations for behavioral science to study positive deviance}

In this article we have proposed a method to study positive deviance in the behavioral sciences. We have suggested adapting Bradley's 4 step process: (1) identifying positive deviants, (2) studying positive deviants, (3) testing interventions based on lessons from positive deviants and (4) testing the generalizability of the 
interventions. Though some of the topics we present here are widely studied in psychology, we argue that the positive deviance approach would unify previously discrete streams of evidence. Specifically, this new orientation shifts the focus of research away from narrow directional hypothesis tests to a robust, iterative framework emphasizing how observed differences can be leveraged to reduce societal inequality, often irrespective of the direction of those differences. We outline this integration explicitly to orient research towards the information required for large-scale intervention. This intervention focus propels psychological research beyond capturing individual differences that distinguish positive deviants from others. Critically, this approach requires naturalistic longitudinal data in order to distinguish true and meaningful positive deviance, data which are rarely utilized in psychology.

When it comes to identifying and operationalizing positive deviants we suggested first determining a baseline group, which is disadvantaged in a domain of interest. Once the baseline is established, positive deviants should be operationalized as people that have sustained positive outcomes relative to baseline group norm. Ideally, these positive outcomes should be captured by multiple indicators, that all measure some aspect of the construct of interest. An operationalization that emphasizes both sustainability and multidimensionality in this way will be robust to edge cases and false positives.

Once positive deviants have been identified, they should be studied quantitatively (ideally over time) to isolate candidate predictors of their success. Potential psychological factors can then be extracted from existing theory. When searching for inflection points and strategies that distinguish positive deviants it is essential to have an appropriate control group in order to guard against survivorship bias.

When researchers have a working hypothesis about the choices and strategies positive deviants utilize to successfully navigate their circumstance they should validate this work by designing interventions that encourage similar behaviors in others. We propose this work is carried out in two stages, first with inconsequential choices, then in real life settings. The purpose of the inconsequential phase is two-fold: first target populations for positive deviance interventions are by definition vulnerable, so it is essential to establish that interventions have no harmful effects before applying them to consequential choices. Second, to ensure 
the efficient use of resources, one needs to establish that the intervention promotes the desired choice pattern before the long-term consequences of these shifts in choice patterns can be evaluated.

While all examples provided here are early-stage cases, some insights allow us to make simple recommendations that should assist with initial efforts to study positive deviance in behavioral science. To begin, we recommend a minimum age cutoff of 35 for the identification of positive deviants in financial contexts, at least in the United States. This allows for sufficient time to assess major life choices and sustained behavioral patterns to compensate for generational poverty or debt associated with lower economic wealth. It also ensures capturing potential positive deviants who may currently be paying off educational debts, while not yet having had time to accumulate meaningful wealth or establish clear choice patterns.

For example, a degree from a highly selective university is one of the surest ways to earn a high income in the US (Chetty et al., 2020), but such an education takes years, and is often associated with debt, so it might take until someone is in their mid-thirties for the value of this investment to clearly manifest. In places where these deficits are less extensive, it may make sense to lower the cutoff to 32 or 30 , though this could risk false positives (i.e., those likely to revert to mean) and false negatives (i.e., those who had more to overcome and therefore require longer to do so).

Another recommendation we make in stronger terms is that work on positive deviance should explicate and emphasize barriers to choices and behaviors that disadvantaged communities face. Specifically, this means not assuming that people who are poor or otherwise disadvantaged due to bad decision-making, or even that positive deviants are purely "better" decision-makers than their peers. Rather, positive deviants may have been in similar circumstances but not faced the same systemic obstruction as others. The reason why positive deviants see better outcomes is an empirical question, and a wide range of hypotheses should be evaluated, especially in this early stage of research.

This has to be a feature of any work on positive deviance, otherwise conclusions may overstate abilities of one group and underestimate or fail to identify the impact of major barriers in those that do not end up with better 
outcomes, including financial well-being. There is little question that race, gender, geography (i.e., urban/rural) will be among the critical correlates of barriers faced and must be a feature of all study on inequalities.

\section{In search of inflection}

To summarize, positive deviance provides a novel, fruitful way to study the psychology of reducing inequality. It is novel because much of the existing literature on the psychology of poverty focuses on the cognitive constraints that follow from scarcity (Haushofer \& Fehr, 2014; Mani et al., 2013; Schilbach et al., 2016). It is fruitful to policymakers because it naturally suggests interventions that are adapted to local contexts and therefore sustainable (Baxter et al., 2016; Bradley et al., 2009; Marsh et al., 2004). It is fruitful to psychologists because the positive deviance framework adds some theoretical structure to the field of behaviorally informed interventions, which has previously been accused of being a loose compilation of methods and anecdotes with no underlying theoretical justification (Choi \& Pritchard, 2003).

As this work proceeds, we strongly recommend that researchers begin with better identification and understanding of positive deviants. If nothing else, to elucidate the most critical inflection points in their trajectories will offer invaluable insights for both science and policy. This could relate to any number of behaviors, whether it is the timing and amount of the first student loan payment for those who were out of debt quickly, or the planning methods used by low-income individuals to maintain good physical health. The most critical indications of positive deviance will likely shed light on both the exceptional nature of choices as well as the harmful barriers - intentional, systematic, or otherwise - that prohibit so many others from experiencing the same positive outcomes. Doing so will have benefits for individuals and societies.

With this writing, we hope to encourage the effective utilization of positive deviance research in psychology. To be clear, advancing research on this topic is not an end in itself. We present this argument because of the potential to provide meaningful new evidence in two primary ways. The first is to increase attention to small but meaningful minority outcomes. For example, in classic social science, finding only a small percentage, say $10 \%$, of a disadvantaged group had achieved a positive outcome would not automatically encourage further 
study of the $10 \%$, only (rightly) highlight the circumstances of the $90 \%$. Incorporating positive deviance into psychological research explicitly aims to determine if something about the circumstances or behaviors of the $10 \%$ may be directly leveraged to support the $90 \%$. Doing so does require widening of methodological approaches in psychology, primarily through incorporating real-world data into study design, and ensuring reliable and equitable intervention outcomes prior to transforming research into policy recommendations.

\section{Conclusion}

The aim of this article was not to present conclusive insights regarding positive deviance, but to encourage robust study of the concept. Our purpose was to highlight the potential impact of applying positive deviance to behavioral science, and in doing so, hopefully generate interest for this approach. There may be a strong desire to rush to developing interventions, but our strong view is that these should not precede a more robust taxonomy for identifying positive deviants. We recommend those studies branch out beyond purely financial topics, as the absence of evidence means there may be a number of potential areas for implementing this framework to produce meaningful scientific insights.

Carrying out this research carefully, responsibly, and reliably will only increase the potential for impact in practice, by quantifying the determinants of positive deviants, their behaviors, and by suggesting ways to improve outcomes through leveraging those insights in a number of domains. It will also serve to highlight those contexts where impact may be less, non-existent, or detrimental to the target populations. In doing so, the ultimate aim of work on positive deviance is to increase positive outcomes such that they are no longer the exception, and instead become the norm, even for those starting in the most difficult circumstances.

Greater utilization of positive deviance in behavioral science may have direct value - particularly for those who may benefit most - toward improving the well-being of individuals and populations.

\section{Acknowledgements}

We wish to acknowledge Susan Yee, Taylor Allen, and Laura Bartkowiak from Community Healthcare

Network. We also thank the Data Science Institute at Columbia University. 


\section{References}

Acs, G., \& Zimmerman, S. (2008). US intragenerational economic mobility from 1984 to 2004: Trends and implications. Pew Charitable Trusts.

Albanna, B., \& Heeks, R. (2019). Positive deviance, big data, and development: A systematic literature review. Electronic Journal of Information Systems in Developing Countries, 85(1), e12063.

Alesina, A., Stantcheva, S., \& Teso, E. (2018). Intergenerational Mobility and Preferences for Redistribution. American Economic Review, 108(2), 521-554.

Arulsamy, K., \& Delaney, L. (2020). The Impact of Automatic Enrolment on the Mental Health Gap in Pension Participation: Evidence from the UK. Working Papers 202004. Geary Institute, University College Dublin.

Atems, B., \& Jones, J. (2015). Income inequality and economic growth: A panel VAR approach. Empirical Economics, 48(4), 1541-1561.

Baker, S. R., Farrokhnia, R. A., Meyer, S., Pagel, M., \& Yannelis, C. (2020). Income, liquidity, and the consumption response to the 2020 economic stimulus payments (No. w27097). National Bureau of Economic Research.

Baxter, R., Taylor, N., Kellar, I., \& Lawton, R. (2016). What methods are used to apply positive deviance within healthcare organisations? A systematic review. BMJ Quality \& Safety, 25(3), 190-201.

Batterham, R. W., Hawkins, M., Collins, P. A., Buchbinder, R., \& Osborne, R. H. (2016). Health literacy: applying current concepts to improve health services and reduce health inequalities. Public Health, 132, 3-12.

Bradley, E. H., Curry, L. A., Ramanadhan, S., Rowe, L., Nembhard, I. M., \& Krumholz, H. M. (2009). Research in action: Using positive deviance to improve quality of health care. Implementation Science, 4(1), 25.

Bryan, C. J., Mazar, N., Jamison, J., Braithwaite, J., Dechausay, N., Fishbane, A., Fox, E., Gauri, V., Glennerster, R., Haushofer, J., Karlan, D., \& Vakis, R. (2017). Overcoming behavioral obstacles to escaping poverty. Behavioral Science \& Policy, 3(1), 80-91.

Baumeister, R., F., Vohs, K. D., \& Funder, D. C. (2017). Psychology as the Science of Self-Reports and Finger Movements: Whatever Happened to Actual Behavior? Perspectives on Psychological Science, 2(4), 396-403.

Carey, R. L. (2019). Am I smart enough? Will I make friends? And can I even afford it? Exploring the collegegoing dilemmas of Black and Latino adolescent boys. American Journal of Education, 125(3), 381-415.

Chaiyachati, K. H., Hubbard, R. A., Yeager, A., Mugo, B., Lopez, S., Asch, E., Shi, C., Shea, J. A., Rosin, R., \& Grande, D. (2018). Association of Rideshare-Based Transportation Services and Missed Primary Care Appointments: A Clinical Trial. JAMA Internal Medicine, 178(3), 383-389.

Chetty, R., Friedman, J., Saez, E., Turner, N., \& Yagan, D. (2020). The determinants of income segregation and intergenerational mobility: Using test scores to measure undermatching. NBER Working Paper, (w26748).

Choi, S. J., \& Pritchard, A. C. (2003). Behavioral Economics and the SEC. Stanford Law Review, 56(1), 1-73.

Cialdini, R. B. (2009). We Have to Break Up. Perspectives on Psychological Science, 4(1), 5-6.

Claro, S., Paunesku, D., \& Dweck, C. S. (2016). Growth mindset tempers the effects of poverty on academic achievement. Proceedings of the National Academy of Sciences, 113(31), 8664-8668.

Daugherty, J. R., \& Brase, G. L. (2010). Taking time to be healthy: Predicting health behaviors with delay discounting and time perspective. Personality and Individual Differences, 48(2), 202-207. 
Davidai, S., \& Gilovich, T. (2016). The headwinds/tailwinds asymmetry: An availability bias in assessments of barriers and blessings. Journal of Personality and Social Psychology, 111(6), 835.1

de Francisco, N., Donadel, M., Jit, M., \& Hutubessy, R. (2015). A systematic review of the social and economic burden of influenza in low-and middle-income countries. Vaccine, 33(48), 6537-6544.

DeNavas-Walt, C., \& Proctor, B. D. (2014). Income and poverty in the United States: 2013. US Government.

Dickman, S. L., Himmelstein, D. U., \& Woolhandler, S. (2017). Inequality and the health-care system in the USA. The Lancet, 389(10077), 1431-1441.

Dietze, P., \& Craig, M.A. (2020). Framing economic inequality and policy as group disadvantages (vs. group advantages) spurs support for action. Nature Human Behaviour.

Evans, A., Dunstan, F., Fone, D. L., Bandyopadhyay, A., Schofield, B., Demmler, J. C., ... \& Paranjothy, S. (2019). The role of health and social factors in education outcome: A record-linked electronic birth cohort analysis. PLoS One, 14(8), e0220771.

Evans, G. W., \& Kim, P. (2013). Childhood poverty, chronic stress, self-regulation, and coping. Child Development Perspectives, 7(1), 43-48.

Feng, Y., \& Bruhn, C. (2016). Food safety education for people with diabetes and pregnant women: A positive deviance approach. Food Control, 66, 107-115.

Flake, J. K., Pek, J., \& Hehman, E. (2017). Construct Validation in Social and Personality Research: Current Practice and Recommendations, 8(4), 370-378.

Frankenhuis, W. E., \& Nettle, D. (2020). The strengths of people in poverty. Current Directions in Psychological Science, 29(1), 16-21.

Franklin, M., Folke, T., \& Ruggeri, K. (2019). Optimising nudges and boosts for financial decisions under uncertainty. Palgrave Communications, 5(1), 1-13.

Gangl, K., van Dijk, W. W., van Dijk, E., \& Hofmann, E. (2020). Building versus maintaining a perceived confidence-based tax climate: Experimental evidence. Journal of Economic Psychology, 81, 102310.

Gary, F. A. (2005). Stigma: Barrier to mental health care among ethnic minorities. Issues in mental health nursing, 26(10), 979-999.

Gennetian, L. A., \& Shafir, E. (2015). The Persistence of Poverty in the Context of Financial Instability: A Behavioral Perspective. Journal of Policy Analysis and Management, 34(4), 904-936.

Gerber, B. S., Cho, Y. I., Arozullah, A. M., \& Lee, S. Y. D. (2010). Racial differences in medication adherence: a cross-sectional study of Medicare enrollees. The American journal of geriatric pharmacotherapy, $8(2)$, 136-145.

Glen, A. (2015). Career Pathways: One City Working Together. NYC Career Pathways.

Gneezy, A., Imas, A., \& Jaroszewicz, A. (2020). The impact of agency on time and risk preferences. Nature Communications, 11(1), 1-9.

Goodin, R. E., Mahmud Rice, J., Parpo, A., \& Eriksson, L. (2008). Discretionary Time: A New Measure of Freedom. Cambridge University Press.

Hadar, L., Sood, S., \& Fox, C. R. (2013). Subjective knowledge in consumer financial decisions. Journal of Marketing Research, 50, 303-316. 
Hadler, J. L., Yousey-Hindes, K., Pérez, A., Anderson, E. J., Bargsten, M., Bohm, S. R., ... \& Lung, K. L. (2016). Influenza-related hospitalizations and poverty levels-United States, 2010-2012. Morbidity and Mortality Weekly Report, 65(5), 101-105.

Harari, Y. N. (2014). Sapiens: A brief history of humankind. Harper Collins.

Harris, L., Lee, V. K., Thompson, E. H., \& Kranton, R. (2016). Exploring the generalization process from past behavior to predicting future behavior. Journal of Behavioral Decision Making, 29(4), 419-436.

Harvey, A. S., \& Mukhopadhyay, A. K. (2007). When twenty-four hours is not enough: Time poverty of working parents. Social indicators research, 82(1), 57-77.

Hasvold, P. E., \& Wootton, R. (2011). Use of telephone and SMS reminders to improve attendance at hospital appointments: A systematic review. Journal of Telemedicine and Telecare, 17(7), 358-364.

Hauff, J. C., Carlander, A., Gärling, T., \& Nicolini, G. (2020). Retirement Financial Behaviour: How Important Is Being Financially Literate? Journal of Consumer Policy, 1-22.

Hauser, O. P., \& Norton, M. I. (2017). (Mis)perceptions of inequality. Current Opinion in Psychology, 18, 21-25.

Haushofer, J., \& Fehr, E. (2014). On the psychology of poverty. Science, 344(6186), 862-867.

Heatherton, T. F., \& Nichols, P. A. (1994). Personal accounts of successful versus failed attempts at life change. Personality and Social Psychology Bulletin, 20(6), 664-675.

Heckert, A., \& Heckert, D. M. (2002). A new typology of deviance: Integrating normative and reactivist definitions of deviance. Deviant Behavior, 23(5), 449-479.

Heilmann, C. (2014). Success conditions for nudges: A methodological critique of libertarian paternalism. European Journal for Philosophy of Science, 4(1), 75-94.

Hertwig, R., \& Grüne-Yanoff, T. (2017). Nudging and Boosting: Steering or Empowering Good Decisions. Perspectives on Psychological Science, 12(6), 973-986.

Hill, H. D., Romich, J., Mattingly, M. J., Shamsuddin, S., \& Wething, H. (2017). An introduction to household economic instability and social policy. Social Service Review, 91(3), 371-389.

Hong, R., Baumann, B. M., \& Boudreaux, E. D. (2007). The emergency department for routine healthcare: race/ethnicity, socioeconomic status, and perceptual factors. The Journal of emergency medicine, 32(2), 149158.

Howlett, M., McConnell, A., \& Perl, A. (2017). Moving policy theory forward: connecting multiple stream and advocacy coalition frameworks to policy cycle models of analysis. Australian Journal of Public Administration, 76(1), 65-79.

IJzerman, H., Lewis, N. A., Jr., Przybylski, A. K., Weinstein, N., DeBruine, L., Ritchie, S. J., ... \& Anvari, F. (2020). Use caution when applying behavioural science to policy. Nature Human Behaviour, 4(11), 1092 1094.

Kahneman, D., \& Tversky, A. (1979). Prospect theory: An analysis of decision under risk. Econometrica, 47(2), 263-292.

Kangovi, S., Barg, F. K., Carter, T., Long, J. A., Shannon, R., \& Grande, D. (2013). Understanding why patients of low socioeconomic status prefer hospitals over ambulatory care. Health Affairs, 32(7), 1196-1203.

Kneebone, E. (2009). Economic recovery and the EITC: Expanding the Earned Income Tax Credit to benefit families and places. Washington, DC: The Brookings Institution Metropolitan Policy Program. 
Kraus, M. W., Onyeador, I. N., Daumeyer, N. M., Rucker, J. M., \& Richeson, J. A. (2019). The misperception of racial economic inequality. Perspectives on Psychological Science, 14(6), 899-921.

Kuhnen, C. M. (2015). Asymmetric learning from financial information. Journal of Finance, 70(5), 2029-2062.

Lang, V. (2020) The economics of the democratic deficit: The effect of IMF programs on inequality. Review of International Organizations. https://doi.org/10.1007/s11558-020-09405-x

Lee, N. C., Krabbendam, L., Dekker, S., Boschloo, A., de Groot, R. H., \& Jolles, J. (2012). Academic motivation mediates the influence of temporal discounting on academic achievement during adolescence. Trends in Neuroscience and Education, 1(1), 43-48.

LeMahieu, P. G., Nordstrum, L. E., \& Gale, D. (2017). Positive Deviance: Learning from Positive Anomalies. Quality Assurance in Education. 25(1), 109-24.

Lewis Jr, N., \& Yates, J. (2019). Preparing disadvantaged students for success in college: Lessons learned from the preparation initiative. Perspectives on Psychological Science, 14(1), 54-59.

Loewenstein, G., \& Chater, N. (2017). Putting nudges in perspective. Behavioural Public Policy, 1(1), 26-53.

Looney, A., \& Yannelis, C. (2015). A crisis in student loans?: How changes in the characteristics of borrowers and in the institutions they attended contributed to rising loan defaults. Brookings Papers on Economic Activity, 2015(2), 1-89.

Ludwig, R.M., Flournoy, J., \& Berkman, E.T. (2019). Inequality in personality and temporal discounting across socioeconomic status? Assessing the evidence. Journal of Research in Personality, 81, 79-87.

Mackintosh, U.A., Marsh, D.R., \& Schroeder, D.G. (2002). Sustained positive deviant child care practices and their effects on child growth in Viet Nam. Food and Nutrition Bulletin, 23(4), 16-25.

Mani, A., Mullainathan, S., Shafir, E., \& Zhao, J. (2013). Poverty Impedes Cognitive Function. Science, 341(6149), 976-980.

Marra, A. R., Guastelli, L. R., Araújo, C. M. P. de, Santos, J. L. S. dos, Lamblet, L. C. R., Silva, M., Lima, G. de, Cal, R. G. R., Paes, Â. T., Neto, M. C., Barbosa, L., Edmond, M. B., \& Santos, O. F. P. dos. (2010). Positive Deviance A New Strategy for Improving Hand Hygiene Compliance. Infection Control \& Hospital Epidemiology, 31(1), 12-20.

Marsh, D. R., Schroeder, D. G., Dearden, K. A., Sternin, J., \& Sternin, M. (2004). The power of positive deviance. BMJ, 329(7475), 1177-1179.

Mejia-Smith, B., \& Gushue, G. V. (2017). Latina/o college students' perceptions of career barriers: Influence of ethnic identity, acculturation, and self-efficacy. Journal of Counseling \& Development, 95(2), 145-155.

Mian, A., \& Sufi, A. (2015). House of debt: How they (and you) caused the Great Recession, and how we can prevent it from happening again. University of Chicago Press.

Mishra, S. I., Gioia, D., Childress, S., Barnet, B., \& Webster, R. L. (2011). Adherence to medication regimens among low-income patients with multiple comorbid chronic conditions. Health \& social work, 36(4), 249-258.

Morduch, J., \& Schneider, R. (2017). The Financial Diaries: How American Families Cope in a World of Uncertainty. Princeton University Press.

Niño-Zarazúa, M., Roope, L., \& Tarp, F. (2017). Global inequality: Relatively lower, absolutely higher. Review of Income and Wealth, 63(4), 661-684.

Norton, M. I., \& Ariely, D. (2011). Building a Better America-One Wealth Quintile at a Time. Perspectives on Psychological Science, 6(1), 9-12. 
Oishi, S., \& Kesebir, S. (2015). Income Inequality Explains Why Economic Growth Does Not Always Translate to an Increase in Happiness. Psychological Science, 26(10), 1630-1638.

Oishi, S., Kesebir, S., \& Diener, E. (2011). Income Inequality and Happiness. Psychological Science, 22(9), 10951100 .

Ortiz, I., \& Cummins, M. (2011). Global Inequality: Beyond the Bottom Billion-A Rapid Review of Income Distribution in 141 Countries. UNICEF, New York.

Östervall, L. W. (2017). Nudging to prudence? The effect of reminders on antibiotics prescriptions. Journal of Economic Behavior and Organization, 135, 39-52.

Pascale, R., Sternin, J., \& Sternin, M. (2010). The Power of Positive Deviance: How Unlikely Innovators Solve the World's Toughest Problems. Harvard Business Press: Boston, MA.

Payne, K. (2017). The broken ladder: How inequality affects the way we think, live, and die. Penguin.

Pew Research Center. (2014). Emerging and Developing Economics Much More Optimistic than Rich Countries about the Future.

Piketty, T. (2015). About capital in the twenty-first century. American Economic Review, 105(5), 48-53.

Richter, I., Thøgersen, J., \& Klöckner, C. A. (2018). A social norms intervention going wrong: Boomerang effects from descriptive norms information. Sustainability, 10(8), 2848.

Ringold, D. J. (2002). Boomerang effects in response to public health interventions: Some unintended consequences in the alcoholic beverage market. Joumal of Consumer Policy, 25(1), 27-63.

Roche, M. L., Marquis, G. S., Gyorkos, T. W., Blouin, B., Sarsoza, J., \& Kuhnlein, H. V. (2017). A community-based positive deviance/hearth infant and young child nutrition intervention in Ecuador improved diet and reduced underweight. Journal of Nutrition Education and Behavior, 49(3), 196-203.

Rose, J. L. (2019). Free time. Princeton University Press.

Ruggeri, K. (2019). Behavioral Insights for Public Policy: Concepts and Cases. Routledge: London and New York.

Ruggeri, K., Alí, S., Berge, M. L., Bertoldo, G., Bjørndal, L. D., Cortijos-Bernabeu, A., ... \& Folke, T. (2020). Replicating patterns of prospect theory for decision under risk. Nature Human Behaviour, 4(6), 622-633.

Ruggeri, K., Benzerga, A., Verra, S., \& Folke, T. (2020a). A behavioral approach to personalizing public health. Behavioural Public Policy, 1-13.

Ruggeri, K., Folke, T., Benzerga, A., Verra, S., Büttner, C., Steinbeck, V., ... \& Chaiyachati, K. (2020b). Nudging New York: adaptive models and the limits of behavioral interventions to reduce no-shows and health inequalities. BMC Health Services Research, 20, 1-11.

Ruggeri, K., van der Linden, S., Wang, Y. C., Papa, F., Riesch, J., Green, J. (2020c). Standards for evidence in policy decision-making. Nature Research Social and Behavioural Sciences, 399005.

Sajquim De Torres, M. (2016). Becoming Resilient: A Positive Deviance Inquiry into the Resilience of Mexican Immigrant Women. Open Access Theses \& Dissertations, 950. Accessed October 21, 2020 at digitalcommons.utep.edu/open_etd/950

Salisbury, L. C., \& Zhao, M. (2020). Active Choice Format and Minimum Payment Warnings in Credit Card Repayment Decisions. Journal of Public Policy \& Marketing, 39(3), 284-304.

Sanders-Phillips, K., Settles-Reaves, B., Walker, D., \& Brownlow, J. (2009). Social inequality and racial discrimination: Risk factors for health disparities in children of color. Pediatrics, 124(Supplement 3), S176-S186. 
Scanlon, T. (2018). Why does inequality matter? Oxford University Press.

Schilbach, F., Schofield, H., \& Mullainathan, S. (2016). The Psychological Lives of the Poor. American Economic Review, 106(5), 435-440.

Schultz, P. W., Nolan, J. M., Cialdini, R. B., Goldstein, N. J., \& Griskevicius, V. (2007). The constructive, destructive, and reconstructive power of social norms. Psychological Science, 18(5), 429-434.

Shah AK, Mullainathan S, \& Shafir E (2012). Some consequences of having too little. Science, 338(6107), 682685.

Singhal, A., \& Dura, L. (2017). Positive deviance: A non-normative approach to health and risk messaging. In Oxford Research Encyclopedia of Communication.

Solga, H. (2014). Education, economic inequality and the promises of the social investment state. SocioEconomic Review, 12(2), 269-297.

Sripaipan, T., Schroeder, D. G., Marsh, D. R., Pachón, H., Dearden, K. A., Ha, T. T., \& Lang, T. T. (2002). Effect of an Integrated Nutrition Program on Child Morbidity due to Respiratory Infection and Diarrhea in Northern Viet Nam. Food and Nutrition Bulletin, 23 (4, supplement 1), 67-74.

Spreitzer, G. M., \& Sonenshein, S. (2004). Toward the construct definition of positive deviance. American Behavioral Scientist, 47(6), 828-847.

Starmans, C., Sheskin, M., \& Bloom, P. (2017). Why people prefer unequal societies. Nature Human Behaviour, 1(4), $1-7$.

Sunstein, C. R. (2017). Nudges that fail. Behavioural Public Policy, 1(1), 4-25.

Sussman, A. B., \& O'Brien, R. L. (2016). Knowing When to Spend: Unintended Financial Consequences of Earmarking to Encourage Savings. Journal of Marketing Research, 53(5), 790-803.

Thaler, R. H., \& Sunstein, C. R. (2009). Nudge: Improving decisions about health, wealth, and happiness. Penguin.

Trafimow, D., \& Finlay, K. A. (1996). The importance of subjective norms for a minority of people: Between subjects and within-subjects analyses. Personality and social psychology bulletin, 22(8), 820-828.

Tyler, T. (2011). Procedural justice shapes evaluations of income inequality: Commentary on Norton and Ariely (2011). Perspectives on Psychological Science, 6(1), 15-16.

Whillans, A. V., Weidman, A. C., \& Dunn, E. W. (2016). Valuing time over money is associated with greater happiness. Social Psychological and Personality Science, 7(3), 213-222.

Wishik, S.M., \& Van der Vynckt, S. (1976). The use of nutritional 'positive deviants' to identify

approaches for modification of dietary practices. American Journal of Public Health, 66(1), 38-42.

Yarkoni, T. (2020). The generalizability crisis. Behavioral and Brain Sciences, 1-37.

doi:10.1017/S0140525X20001685

Zanetti, C. A., \& Taylor, N. (2016). Value co-creation in healthcare through positive deviance. Healthcare, 4(4), 277-281.

Zeitlin, M., Ghassemi, H., \& Mansour, M. (1990). Positive Deviance in Child Nutrition. United Nations University Press: Tokyo. 